\title{
Preface: Land subsidence processes
}

\author{
Devin L. Galloway ${ }^{1} \cdot$ Gilles Erkens $^{2,3}$. \\ Eve L. Kuniansky ${ }^{4}$. Joel C. Rowland ${ }^{5}$
}

Received: 7 February 2016 / Accepted: 11 February 2016 /Published online: 4 March 2016

(C) Springer-Verlag Berlin Heidelberg (outside the USA) 2016

\section{Introduction}

Both natural and anthropogenic land subsidence are global phenomena caused by a variety of factors, many of which are related to hydrogeologic processes. Common natural subsidence processes include consolidation related to sediment loading, tectonics, volcanism, and dissolution of relatively soluble carbonate and evaporite minerals. Some natural subsidence processes are directly influenced by human activities related to land and water use and by climatic variability. The development of water resources to support human habitation and cultivation for agriculture typically results in the use and diversion of available surface-water supplies and a reliance on groundwater supplies. These practices can alter the natural hydrologic system in ways that amplify natural subsidence processes or create new anthropogenic subsidence. For example, engineered diversion of runoff can focus recharge in areas susceptible to mineral dissolution which can lead to sinkholes or other collapse features in the karst landscape, or engineered

Published in the theme issue "Land Subsidence Processes"

Devin L. Galloway

dlgallow@usgs.gov

1 US Geological Survey, 5957 Lakeside Blvd., Indianapolis, IN 46278, USA

2 Deltares Research Institute, 8 P.O. Box 85467, 3508 AL Utrecht, The Netherlands

3 Department of Physical Geography, Utrecht University, P.O. Box 80115, 3508 TC Utrecht, The Netherlands

4 US Geological Survey, 1770 Corporate Dr., Ste. 500, Norcross, GA 30093, USA

5 Los Alamos National Laboratory, Los Alamos, NM 87545, USA drainage of wetlands or saturated organic soils can cause oxidation and consolidation of the soils. Anthropogenic groundwater abstraction from susceptible (generally, unconsolidated alluvial, fluvial and lacustrine sediments) aquifer systems to support water use principally for agriculture, municipal-industrial and energy development typically can lead to local and regional groundwater storage depletion and accompanying aquifersystem compaction and land subsidence related to increases in effective stresses caused by groundwater-level declines. Note that the terms 'compaction', commonly used by geologists, and 'consolidation', commonly used in soil mechanics, are used interchangeably in this preface and theme issue.

Climate variation in terms of global warming, whether natural or anthropogenic, can indirectly cause glacial isostatic adjustments (uplift and subsidence) of the Earth's crust related to melting of ice sheets, or can thaw permafrost with subsequent loss of ice volume and drainage of shallow groundwater leading to mechanical and even oxidation mediated subsidence. Climate variation may result in either reductions (droughts) or enhancements (wet periods) of precipitation, surface runoff and groundwater recharge. These reductions can cause subsidence owing to lowered groundwater levels contributing to aquifersystem compaction and to oxidation and consolidation of organic soils; enhancements can cause subsidence owing to increased dissolution of karst minerals and reduced mechanical support for pre-existing karst features.

The 14 articles (13 papers and one essay) constituting this theme issue address several of the subsidence processes where human use of natural resources and climate variability have combined to create critical anthropogenic land subsidence problems: oxidation and consolidation of organic soils (three articles), dissolution and collapse of carbonate and evaporite rocks (karst) (three articles), thawing permafrost (thermokarst) (one article) and aquifer-system compaction (seven articles). Each of these subsidence processes is intricately related to the 
interaction between groundwater flow, material deformation and/or mass wasting of the skeletal matrix of the groundwaterflow system. Though the importance of understanding the hydrogeologic factors governing the subsidence processes is evident with respect to the attendant hazards, it is important to underscore the broad relation between hydrogeology and hydrology (including surface-water and atmospheric processes). For example, subsidence is directly related to surface-water drainage, in terms of discharge from the groundwater-flow system for organic-soil subsidence, and in terms of recharge to the groundwater-flow system for karst; and for aquifersystem compaction, groundwater flow is related to surfacewater availability in terms of how much groundwater is abstracted. Thermokarst subsidence is related to melting of ground ice, drainage of thawed pore spaces and physical collapse of soils in response to atmospheric warming.

The contributed articles represent subsidence research from study areas in seven countries-Israel, Mexico, the Netherlands, Peoples Republic of China, Saudi Arabia, Spain, and the United States of America - as well as general global study areas. They highlight the importance of improved understanding of the subsidence processes and the hydrogeology and hydrology of the affected groundwater flow systems to reduce subsidence and the related geohazards. In coastal areas, where deltas and estuaries are affected by organic-soil subsidence (Erkens et al.; Deverel et al.; Higgins) or aquifersystem compaction (for example, in China, the Ye et al. "Shanghai 3D model" and the Luo et al. "Shanghai 1D model"), the contribution of anthropogenic subsidence to the rate of relative sea-level rise can be significant, and in some cases for some periods can exceed the rate of eustatic sea level rise by as much as an order of magnitude or more. In inland areas affected by aquifer-system compaction, in many cases as much as several meters (the second Ye et al. paper, on "China subsidence"; Tessitore et al.) and in some cases as much as 9 $\mathrm{m}$ (Faunt et al.) or more of cumulative historical subsidence has occurred. The related geohazards include coastal and riverine flooding, damages to civil infrastructure (buildings, roadways, railways, levees and other flood control structures, water and waste-water conveyances, etc.), and ecosystem degradation. Induced earth fissures and movements on preexisting faults accompanying aquifer-system compaction and large groundwater-level declines pose similar hazards, including providing pathways for contaminated surface waters to reach the shallow groundwater system (Conway; and the Ye et al. paper on "China subsidence").

Knowledge of the subsidence (detection), its extent (mapping), processes, cause-and-effect relations with respect to the use of natural resources (particularly water- and land-use practices), and the realized and potential hazards motivate attempts to minimize the hazards while maximizing the beneficial use of the resources. The research presented in the theme issue papers provides scientists, resource managers and other stakeholders with critical information to increase awareness and understanding of subsidence and the related consequences, and to inform improved management of the resources. More specific information regarding each of the subsidence processes covered in this theme issue and the related contributed papers is presented in the following.

\section{Oxidation and consolidation of organic soils}

Organic soils tend to be very compressible. They are also a common soil type, present both in upland settings (boreal peat bogs, upstream river valleys or filled-in lakes) and in many deltas and coastal zones. In coastal peatlands, the organic deposits are generally thick, formed under conditions of eustatic sea level rise (Erkens et al.). Subsidence of peatlands in the coastal setting is critical, because any loss in elevation in these already low-lying lands increases flood risk. Differential subsidence in peatlands causes damage to infrastructure, embankments, and constructions (Higgins).

Under natural circumstances, a coastal plain or delta represents a dynamic balance between the creation of accommodation space (the space available for potential sediment accumulation) on the one hand and sedimentation on the other. The sediment bodies that are formed in this particular environment are typically clastic (often sandy and/or muddy), but peat is an important constituent as well, depending on clastic sediment inputs and biological production. Both clay and peat deposits consolidate during deposition or subsequent soil formation, but the resulting subsidence is counterbalanced by the addition of organic material and/or sediments. This natural balance has been globally disturbed by human interference. Coastal areas and deltas are amongst the most intensively used areas in the world, hosting ever-growing urban areas and forming important agricultural areas (Higgins). To cultivate the rich organic soils, the peatlands are drained, which immediately stops peat accumulation. The lowered water table causes aeration and shrinkage of the peat soil and the intruding oxygen fuels the bio-chemical decomposition of the peat (oxidation). Peat oxidation results in volume reduction (subsidence) and $\mathrm{CO}_{2}$ gas emissions. In addition, the drained peat loses its buoyancy and loads the underlying peat that starts to consolidate, resulting in further subsidence. Whereas shrinkage and consolidation contribute mostly to subsidence in the first years after drainage, the oxidation component gains relative importance over time because it continues as long as there is peat present above the water table (Deverel et al., Erkens et al.).

The greatest subsidence rates are reported from tropical peatlands, which can subside as much as $5 \mathrm{~cm} /$ year. Over time, specifically when water tables are continuously lowered, cumulative subsidence of several meters can cause coastal peatlands to sink below mean sea level. This happened for instance in the Sacramento-San Joaquin Delta in California, 
USA (Deverel et al.), and the coastal peatlands of the Netherlands (Erkens et al.). Both areas now rely on careful water management. Only permanent flooding of the peatlands (rewetting) will stop subsidence, but traditional agricultural use will be limited under these conditions. Deverel et al. discuss rice growth as an option to mitigate or even reverse subsidence, and present an evaluation of the effects of land-use change on subsidence based on measurements and modeling. Insights into the effectiveness of management strategies are of value for deltas and coastal plains elsewhere. Higgins reviews the multiple causes for land subsidence in deltas and shows that in many cases, organic soil subsidence is just one of the processes contributing to changes in elevation. To improve predictions of subsidence in deltas, numerical models of individual subsidence components must thus be coupled (Higgins).

\section{Dissolution and collapse of carbonate and evaporite rocks}

Subsidence from sinkhole collapse is a common occurrence in areas underlain by water-soluble rocks such as carbonate and evaporite rocks. Typical of karst terrain is a landscape with features such as sinkholes, sinking streams, and springs, which reflect the presence of subsurface voids or caves. The term 'karst' has been expanded to include both features that reflect surficial dissolution processes (epigenic karst), and more recently, features that reflect dissolution processes at depth (hypogenic karst); both result in subsurface voids with the potential for subsidence, sudden sinkhole collapse, or cave development. Knowing when a catastrophic event will occur is not possible; however, understanding where such occurrences are likely is possible owing to the mapping of areas underlain by water-soluble rocks at national and global scales. Numerous studies and engineering projects related to understanding the processes of subsidence in karst and the mitigation of the hazards posed by karst for construction projects are cited within the papers of this special issue (Yechieli et al.; Kuniansky et al.; Youssef et al.). Detailed information on land subsidence processes in karst are included in all three papers, with illustrations of methods used to study these processes included in the papers on subsidence in Saudi Arabia (Youssef et al.) and Israel (Yechieli et al.).

\section{Thawing permafrost}

Warming at high latitudes has triggered widespread landsurface changes in permafrost regions. In permafrostdominated landscapes, this has led to the melting of ground ice and thawing of frozen soils. The loss of ice volume and drainage of soils leads to soil compaction and localized collapse of the ground surface: thermokarst. In their essay, Rowland and Coon examine two recent advancements that will greatly increase our understanding of the rate, magnitude and distribution of thermokarst development. These advancements include the development of numerical models capable of simulating coupled thermo-hydrological processesfreeze/thaw dynamics and groundwater flow in porous media, and the increased availability of high-resolution remotely sensed data for the detection of land-surface change across high latitudes. These advancements provide complementary tools for the advancement of thermokarst research from descriptive to predictive studies.

\section{Aquifer-system compaction}

The compaction of susceptible aquifer systems, the accompanying subsidence, and, in many cases, ground ruptures (earth fissures and movement induced on surface faults) are prevalent and widespread phenomena in developed aquifer systems. Owing to the hydromechanical coupling of groundwater flow and compressibility of the skeletal matrix of an aquifer system (principally through hydraulic head and storage), all aquifer systems deform to some degree when subject to stresses related to changing groundwater levels. This deformation is typically elastic (reversible) and results in only small ground displacements; measureable vertical displacements at land surface of 10-20 mm are fairly common in response to pumping cycles for large production wells. Unconsolidated (alluvial, fluvial and lacustrine sediments) aquifer systems with a significant proportion of the relatively compressible fine-grained (silt and clay sized particles) sedimentary deposits, that are either dispersed or organized in discrete sedimentary units (laterally discontinuous interbeds or laterally extensive confining units) in the aquifer system, typically compact a considerable degree when subject to head declines that exceed critical levels. Much of this compaction is attributed to the inelastic deformation of the fine-grained sediments, and much of the accompanying subsidence is permanent.

The seven contributed papers for this subsidence process emphasize the importance of mapping and monitoring subsidence and any related ground ruptures accompanying aquifersystem compaction. Many of the papers describe research that makes use of borehole-extensometer measurements of aquifer-system compaction, and global navigation satellite system (GNSS) and interferometric synthetic aperture radar (InSAR) measurements of land subsidence. Ground ruptures are prominently featured in papers by Conway (for Arizona, USA) and Carreón-Freyre et al. (for Querétaro, Mexico). The Ye et al. paper on "China subsidence" includes ground ruptures in the overview of subsidence caused by aquifersystem compaction in China. Modeling of aquifer-system compaction and land subsidence is the focus of papers by $\mathrm{Ye}$ 
et al. ("Shanghai 3D model"), Luo et al., and Tessitore et al. Modeling is a significant component of the Faunt et al. and Carreón-Freyre et al. papers. The modeling approaches are based on the 'principle of effective stress' and weakly-tostrongly hydraulically coupled deformation of the aquifer system using simplified approaches embodied in the 'aquitard drainage model' simulated by the U.S. Geological Survey MODFLOW subsidence packages (Faunt et al.) and by MInvCOMPAC (Luo et al.), and more rigorously coupled approaches based on variations of the 'Biot' formulation (Carreón-Freyre et al.; the Ye et al. "Shanghai 3D model" paper; Tessitore et al.). The paper by Carreón-Freyre et al., which focuses on simulating failure of well casings, also demonstrates use of 3D and 2D hydromechanical models to compute stress fields near pre-existing ground ruptures to estimate potential movement on these structures. The models indicate the importance of considering stress-strain on and near faults in subsiding groundwater basins that are compartmentalized by faults.

\section{Summary and conclusions}

Advances in the detection, measurement and mapping of land subsidence over the approximately past two decades, in terms of the development and application of GNSS and InSAR techniques, have dramatically improved capabilities to both identify and scientifically characterize subsidence processes, and increased awareness of the extant and burgeoning subsidence problems throughout the world. This is especially true for subsidence accompanying aquifer-system compaction and the drainage of organic soils. The ongoing development of global land and water resources has resulted in everincreasing instances of subsidence-affected areas.

Enhanced measurement and monitoring capabilities have led to improved constraints on models of subsidence processes. Process models applied to subsidence affected areas are essential to improve understanding of historical subsidence and to predict potential future subsidence. Development of the modeling tools underscores the need for adequate characterization of the geologic and hydrogeologic properties governing the subsidence processes. For some subsidence processes, especially aquifer-system compaction in groundwater systems prone to earth fissures or affected by faulting, the simulation of 3D coupled deformation of the aquifer system and the fissures and faults is becoming more important. This has led to more rigorous and complex process models and underscores the need for more 3D displacement data to constrain these models. Vertical displacement measurements traditionally obtained from geodetic, borehole extensometer and InSAR methods need to be supplemented with corresponding horizontal displacement measurements which typically are less available and more difficult to obtain in spatially (at land surface and at depth) distributed measurement networks. In summary, models are essential tools to improve management of the land and water resources, and mitigation of geohazards accompanying exploitation of the resources.

Taken together, measurement, monitoring and modeling of subsidence processes exemplified in the collection of articles in this theme issue inform resource managers attempting to balance resource usage with the consequences of that usage. The optimal balance between risk and benefit of resource utilization is being sought in many subsidence affected areas. These efforts generally seek to obtain some level of sustainable use of the resources, which typically is best defined by the resource managers in concert with local stakeholders, and takes the form of maximizing beneficial uses while minimizing perceived unacceptable consequences. Subsidence affected areas where these considerations are in play are fairly rare but becoming more prevalent. Commonly, in affected areas, stakeholders are largely insensitive to the problems and resource managers may only be in the early stages of evaluating the problems. Resource managers and stakeholders in these areas can benefit greatly from experiences gained in affected areas that are further along in the scientific evaluation and informed management of the resources. It is hoped that readers (scientists, resource managers and other stakeholders alike) will find relevant transfer value in the elucidation of the particular subsidence processes, their scientific characterization and the various approaches taken to address and manage the subsidence problems presented herein. 